\title{
Graphene Channel Liquid Container Field Effect Transistor as pH Sensor
}

\author{
Xin Li, ${ }^{1}$ Junjie Shi, ${ }^{1}$ Junchao Pang, ${ }^{1}$ Weihua Liu, ${ }^{1}$ Hongzhong Liu, ${ }^{2}$ and Xiaoli Wang ${ }^{1}$ \\ ${ }^{1}$ Department of Microelectronics, Xian Jiaotong University, Xian 710049, China \\ ${ }^{2}$ State Key Laboratory for Manufacturing Systems Engineering, Xian Jiaotong University, Xian 710049, China \\ Correspondence should be addressed to Xin Li; lx@mail.xjtu.edu.cn
}

Received 4 August 2014; Accepted 14 December 2014; Published 31 December 2014

Academic Editor: Rakesh K. Joshi

Copyright (c) 2014 Xin Li et al. This is an open access article distributed under the Creative Commons Attribution License, which permits unrestricted use, distribution, and reproduction in any medium, provided the original work is properly cited.

\begin{abstract}
Graphene channel liquid container field effect transistor $\mathrm{pH}$ sensor with interdigital microtrench for liquid ion testing is presented. Growth morphology and pH sensing property of continuous few-layer graphene (FLG) and quasi-continuous monolayer graphene (MG) channels are compared. The experiment results show that the source-to-drain current of the graphene channel FET has a significant and fast response after adsorption of the measured molecule and ion at the room temperature; at the same time, the FLG response time is less than $4 \mathrm{~s}$. The resolution of MG (0.01) on $\mathrm{pH}$ value is one order of magnitude higher than that of FLG (0.1). The reason is that with fewer defects, the MG is more likely to adsorb measured molecule and ion, and the molecules and ions can make the transport property change. The output sensitivities of MG are from $34.5 \%$ to $57.4 \%$ when the $\mathrm{pH}$ value is between 7 and 8 , while sensitivity of FLG is $4.75 \%$ when the $\mathrm{pH}=7$. The sensor fabrication combines traditional silicon technique and flexible electronic technology and provides an easy way to develop graphene-based electrolyte gas sensor or even biological sensors.
\end{abstract}

\section{Introduction}

Graphene is becoming an attractive nanostructure with many remarkable electronic, optical, chemical, and mechanical properties since its discovery $[1,2]$. As a unique twodimensional nanomaterial, graphene has extremely large surface-to-volume ratio, shows exceptionally high electron mobility at room temperatures, and is sensitive to molecular adsorption [3-12]. Graphene is also a biocompatible sensing material $[8,13]$. Schedin et al. [14] have demonstrated that graphene could even detect individual molecules and allows high signal-to-noise ratio due to the fact that graphene carrier mobility is very high. Namely, the high conductivity and few crystal defects enable a few extra electrons to cause notable changes in carrier concentration of graphene and sensor signal. It is worth mentioning that the extremely high breaking strength $\sim 130 \mathrm{GPa}$ allows graphene to be suspended across a trench about micron size in width $[15,16]$. In recent years, Cheng et al. [16] have demonstrated a suspended graphene sensor in aqueous solution in comparison with that of nonsuspended graphene sensor, to display an improved signal-to-noise ratio.
Having a $\mathrm{pH}$ sensor which can reliably measure values in the range of 7.35-7.45 is extremely important in medicine as normal human body has $\mathrm{pH}$ values in this range and changes in this value can indicate a potential health hazard. In this work, we demonstrate two kinds of graphene film to serve as channel of field effect transistor (FET) used as $\mathrm{pH}$ sensors, in which graphene films cover microtrench to construct liquid ion container inhaling $\mathrm{pH}$ buffer solution. Growth morphology and $\mathrm{pH}$ sensing properties of both continuous few-layer graphene (FLG) and quasi-continuous monolayer graphene (MG) channels are compared and the type of graphene suitable for high resolution $\mathrm{pH}$ value testing is investigated.

\section{Experiment}

Graphene used here is synthesized in our laboratory on copper and nickel foils using low pressure chemical vapor deposition (CVD) method [17]. A schematic of the graphene channel liquid container FET with microtrench is illustrated in Figure 1(a). 


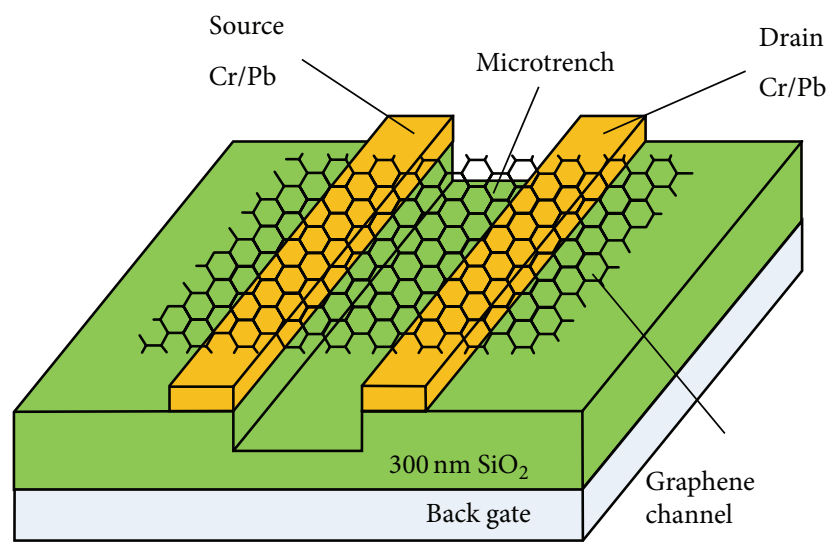

(a)

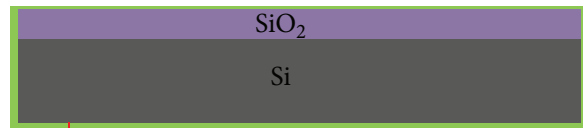

Photolithography

(1)

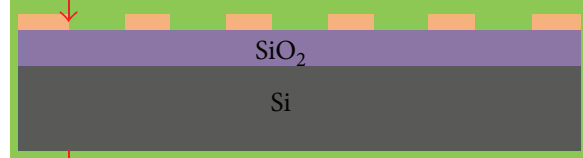

Sputtering metal

(2)
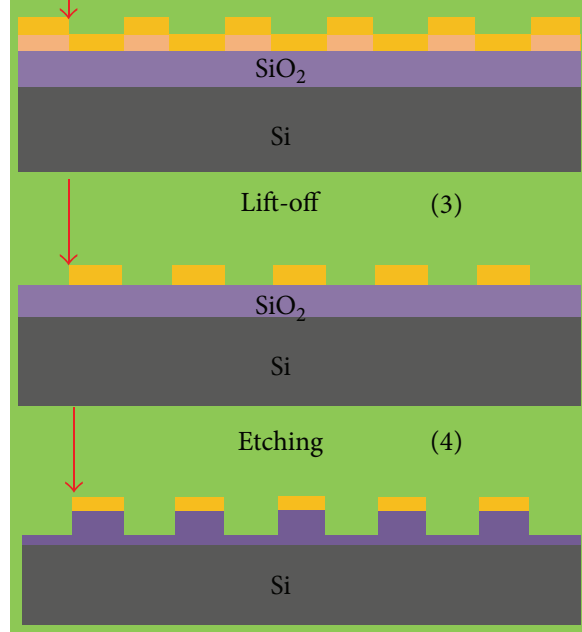

Suspended graphene

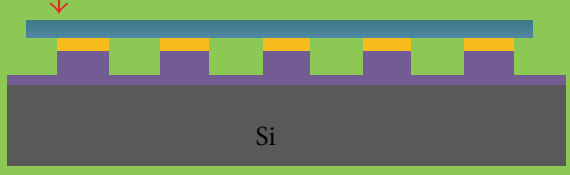

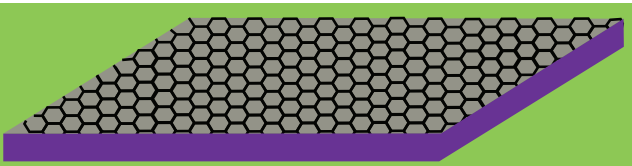

Spin-coating PDMS

(6)

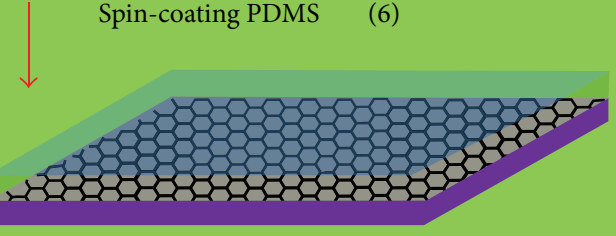

Etching Cu foils

in $\mathrm{FeCl}_{3}$ solution

(7)

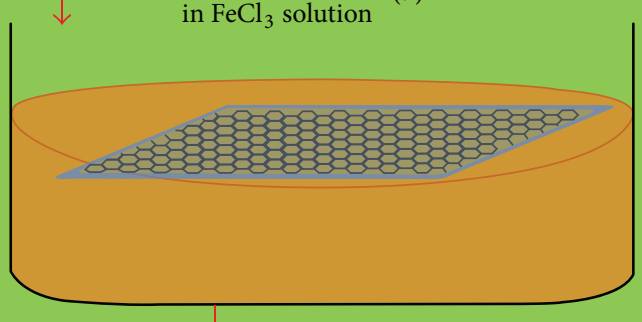

Depositing graphene/PDMS on device

(8)

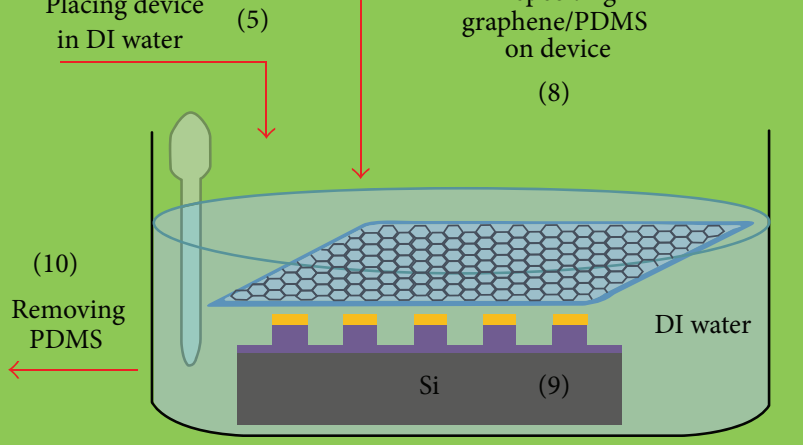

(b)

Figure 1: Schematic diagram (a) and fabrication flowchart (b) of the graphene channel liquid container FET with microtrench. (a) The microtrench is formed on a $300 \mathrm{~nm}$ thick $\mathrm{SiO}_{2}$ layer between the source and drain electrodes and $\mathrm{N}^{+}$heavy doped silicon substrate. Graphene films cover the top and bridge the source and drain electrodes. The testing molecule would be bound to double sides of suspended graphene. (b) Fabrication procedure. Steps (1) to (5) depict the fabrication of interdigital source and drain electrodes on microtrench using lift-off and etching process. Steps (6) to (8) show the transferring graphene on the PDMS film. Steps (9) and (10) show the final result that graphene film covers microtrench to achieve FET device. 


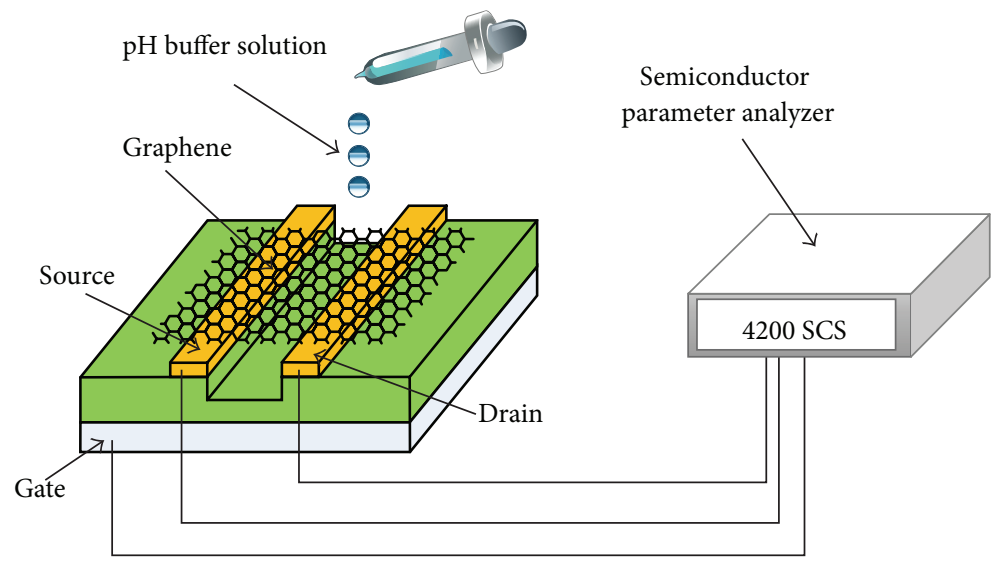

FIGURE 2: Schematic diagram of experiment setup for $\mathrm{pH}$ value testing.

The $\mathrm{SiO}_{2}$ layers between the source and drain electrodes are etched down to form a microtrench. Graphene was cleaned with deionized (DI) water, dried in nitrogen, and transferred by the polymer-support transfer method [18-21] upon the top of the electrodes, thus bridging the source and drain electrodes. The substrate used here is an $\mathrm{N}^{+}$doped silicon substrate with a $300 \mathrm{~nm}$ thick $\mathrm{SiO}_{2}$ layer above. The flowchart of the sensor fabrication is depicted in Figure 1(b). Firstly, we have fabricated interdigital source and drain electrodes on microtrench using lift-off and etching process in steps (1) to (5). The wet etching method was used to form microtrench. Secondly, the graphene film was grown and transferred to the PDMS film in steps (6) to (8). Finally, we achieved the graphene channel liquid container FET after the microtrench was covered by graphene film in steps (9) and (10).

The $\mathrm{pH}$ value measurements setup is shown in Figure 2. Buffer solutions with $\mathrm{pH}$ from 13 to 7 were obtained by diluting alkaline solution. A drop of buffer solution is then dispersed on graphene layer. A semiconductor parameter analyzer (Keithley Instruments, Inc., 4200 SCS) was used to monitor the current between source and drain $I_{\mathrm{DS}}$ of the suspended graphene channel FET during the test. Various concentrations of buffer solutions were introduced to the trench and graphene manually via injection at the humidity of $26 \%$ and temperature of $25^{\circ} \mathrm{C}$. The DI water was introduced to trench and graphene for recovery process. The crystal structure of the graphene is investigated using scanning electron microscopy (SEM) (S-4800 field emission scanning electron microscope). Raman spectra were collected by Horiba Jobin Yvon HR 800 using a $514 \mathrm{~nm}$ laser excitation. Raman spectra were fitted by Voigt function using peak fitting function of Origin 9.0 .

\section{Results and Discussion}

3.1. Characterizations of Two Kinds of Graphene. Graphene is obtained on two kinds of substrates with different surface morphology and structure. SEM analysis is used to determine the morphology and size of as-prepared graphene. Graphene grown on nickel substrate is a large area of continuous film with some white fold on surface as shown in Figure 3(a). The quality and thickness of the graphene were further measured by Raman spectrum (Figure 3(a) inset). The $\mathrm{G}$ band and the $2 \mathrm{D}$ band have peaks at around $1580 \mathrm{~cm}^{-1}$ and $2667 \mathrm{~cm}^{-1}$, respectively. The as-prepared graphene has good quality and low defect density because it contains obvious characteristic 2D peak and invisible D peak (defect peak around $1350 \mathrm{~cm}^{-1}$ ). Few-layer graphene (FLG) on nickel is found to have less than 10 layers, because the $I_{2 \mathrm{D}} / I_{\mathrm{G}}$ ratio is about 0.5. Graphene grown on copper substrate is quasi-continuous film composed of high density ordered hexagonal single crystal graphene domain as shown in Figure 3(b), in which diagonal size is greater than 100 microns. The $\mathrm{G}$ band and the $2 \mathrm{D}$ band have peaks at around $1584 \mathrm{~cm}^{-1}$ and $2663 \mathrm{~cm}^{-1}$, respectively. The $I_{2 \mathrm{D}} / I_{\mathrm{G}}$ ratio is about 2.5 (Figure $3(\mathrm{~b})$ inset). These results confirmed that the graphene on copper is single crystal and monolayer graphene (MG) without defect peak. Both continuous FLG and quasi-continuous MG (greater than $100 \mu \mathrm{m}$ ) can cover the microtrench and bridge source and drain electrodes, because the width of microtrench is less than $20 \mu \mathrm{m}$. White interdomain and fold are clearly visible when quasi-continuous MG film covers microtrench as shown in Figure 3(c).

3.2. $p H$ Value Measurement. Continuous FLG film is used in large range $\mathrm{pH}$ value experiment. When $\mathrm{pH}$ buffer solution flows into the trench, the ions in liquids (charged molecules) would be bound to the double sides of suspended FLG surface to change the conductance of graphene, which in turn modulates the source-to-drain current. The source-to-drain current $I_{\mathrm{DS}}$ response with time in $\mathrm{pH}$ buffer solution under different $\mathrm{pH}$ value is shown in Figure 4(a). The $I_{\mathrm{DS}}$ changed instantly when the $\mathrm{pH}$ buffer solution was inhaled into the microtrench. Altogether it takes about 1 to 4 seconds to reach a relatively stable value. It follows a typical exponential decay process, with a final equilibrium status between adsorption and desorption of $\mathrm{OH}^{-}$, which is the main cause in absorption. The response time constant $\tau$ is estimated to be about $3.11 \mathrm{~s}, 3.55 \mathrm{~s}, 3.56 \mathrm{~s}$, and $3.7 \mathrm{~s}$ for a testing solution of $\mathrm{pH}$ values of $7.0,10.0,11.0$, and 13.0 , respectively. 


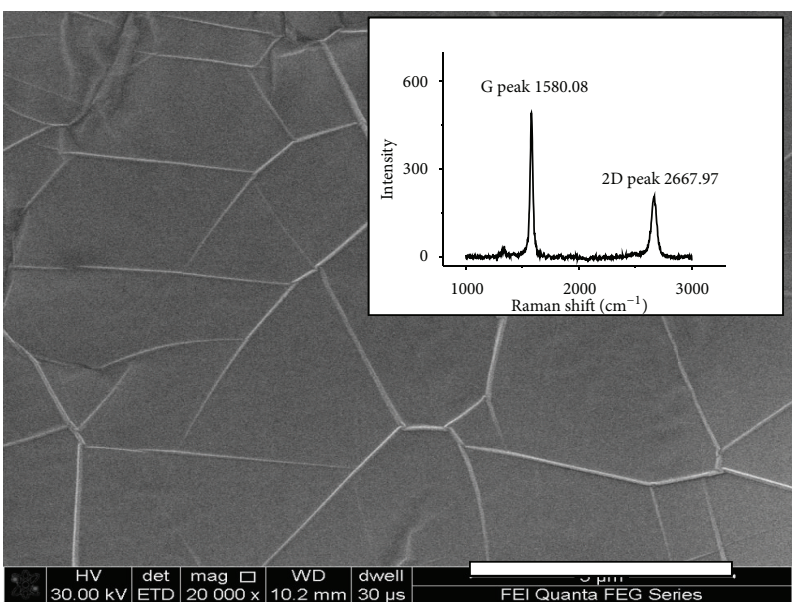

(a)

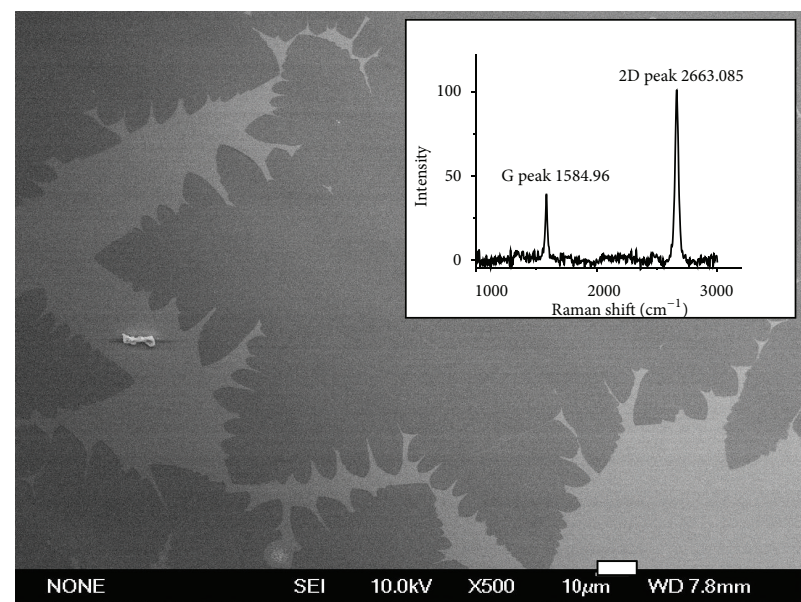

(b)

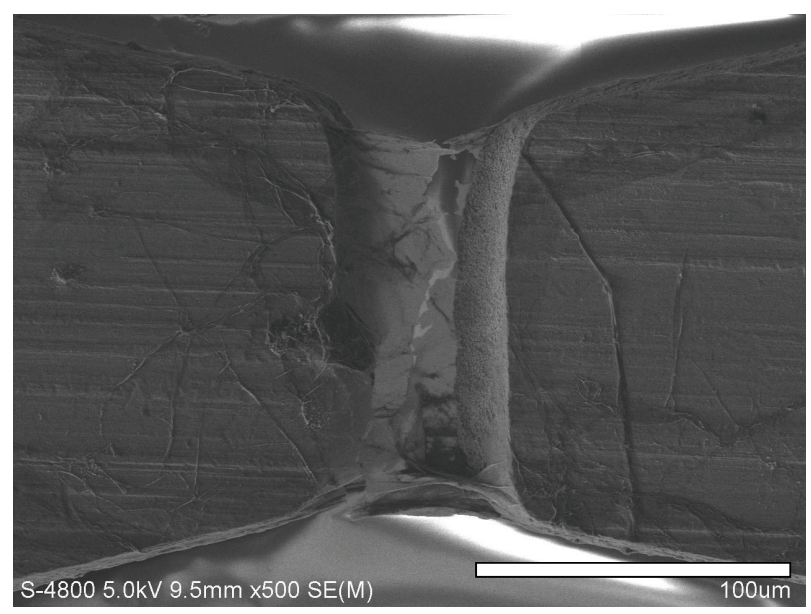

(c)

Figure 3: SEM image of graphene on $\mathrm{Ni}$ and $\mathrm{Cu}$ substrate and Raman spectra of graphene transferred onto $\mathrm{SiO}_{2} / \mathrm{Si}$ substrate. (a) $\mathrm{SEM}$ and Raman spectra (inset figure) of FLG on Ni substrate; the scale bar is $10 \mu \mathrm{m}$. G band and 2D band are peaked at around $1580 \mathrm{~cm}^{-1}$ and $2667 \mathrm{~cm}^{-1}$, respectively. The $I_{2 \mathrm{D}} / I_{\mathrm{G}}$ ratio is about 0.5. (b) SEM and Raman spectra (inset figure) of MG on Cu substrate; G band and $2 \mathrm{D}$ band are peaked at around $1584 \mathrm{~cm}^{-1}$ and $2663 \mathrm{~cm}^{-1}$, respectively, with invisible D peak. The $I_{2 \mathrm{D}} / I_{\mathrm{G}}$ ratio is about 2.5. (c) SEM image of microtrench coating with suspended MG that bridges source and drain electrodes. The scale bar is $100 \mu \mathrm{m}$.

The initial value $I_{\mathrm{DSINI}}$ is not at the same starting point because the desorption of $\mathrm{OH}^{-}$is not complete. Sensitivity $S$, which is defined as $S=\left(I_{\mathrm{DS}}-I_{\mathrm{DSINI}}\right) / I_{\mathrm{DSINI}}$, clearly shows contrast at each pH value and is shown in Figure 4(b). Sensitivity increases almost linearly with the increase of $\mathrm{pH}$ value of the solution suggesting that the $\mathrm{OH}^{-}$absorption of the graphene is still far away from saturation in the tested region of curve, so we could look forward to extending the linear range. The $\mathrm{OH}^{-}$group has an unpaired electron and would trap electrons $[8,9]$ from FLG. Comparing with reported p-type channel of SiNWs or CNTs [16, 22-24], the $I_{\mathrm{DS}}$ of the FLG channel decreased with $\mathrm{pH}$ values increasing, which further confirms that the prepared FLG channel of FET sensor is n-type. The $S$ are $4.75 \%, 24.65 \%, 31.63 \%$, and $45.1 \%$, corresponding to $\mathrm{pH}$ values of 7.0,10.0,11.0, and 13.0, respectively. The $\mathrm{pH}$ value resolution of continuous FLG film is 0.1 .

In order to investigate $\mathrm{pH}$ value resolution of quasicontinuous MG channel liquid container FET, small range experiment between $\mathrm{pH}=7.00$ and $\mathrm{pH}=8.00$ was carried out as shown in Figures 5(a) and 5(b). The $I_{\mathrm{DS}}$ takes about 10 to 25 seconds to reach a relatively stable value when the $\mathrm{pH}$ buffer solution was introduced into the microtrench and response time constant $\tau$ is estimated to be about $22.42 \mathrm{~s}, 11.72 \mathrm{~s}$, and $14.82 \mathrm{~s}$ for $\mathrm{pH}$ values of 7.35, 7.59, and 7.86, respectively. Sensitivity increases almost linearly with the increase of $\mathrm{pH}$ value, and $S$ are $34.5 \%, 47.6 \%$, and $57.4 \%$, corresponding to $\mathrm{pH}$ values of 7.35, 7.59, and 7.86, respectively. For FLG channel, the output sensitivity of FET is $4.75 \%$ when the $\mathrm{pH}=7.0$. Notably, for the quasi-continuous MG channel, the output sensitivities are from $34.5 \%$ to $57.4 \%$ when the $\mathrm{pH}$ value is between 7.00 and 8.00 , which increase nearly one order of magnitude. The reason is that with fewer defects the MG can adsorb more measured molecules and ions than the FLG in the similar ambient. MG is suitable for normal human body $\mathrm{pH}$ values testing, which are 7.35 7.45. The $\mathrm{pH}$ value resolution of quasicontinuous MG film is 0.01 . 


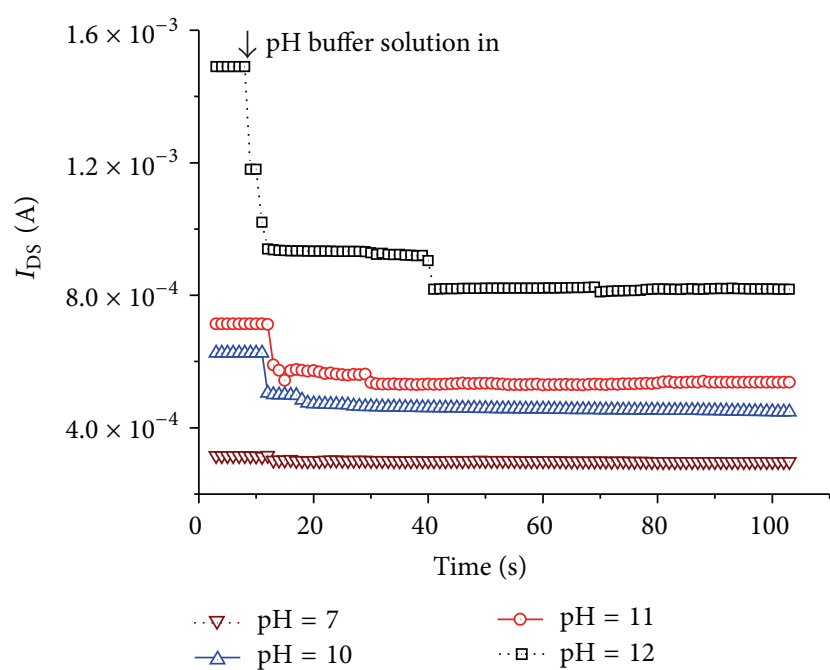

(a)

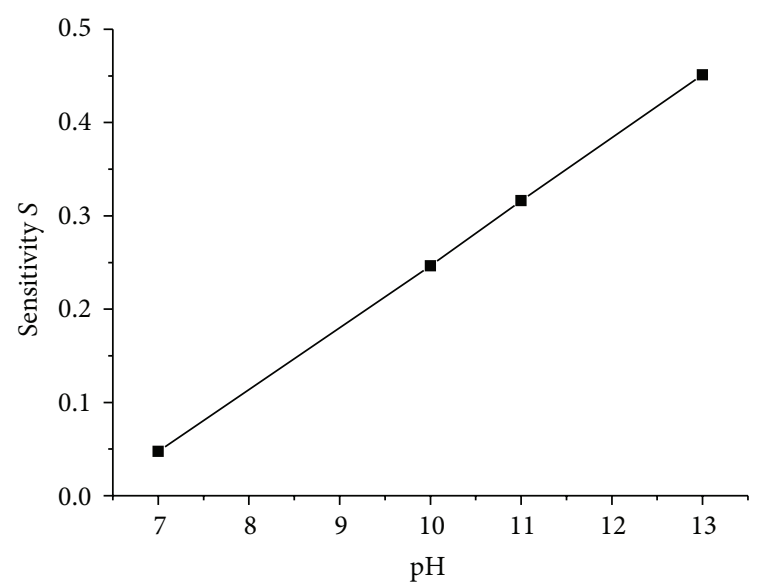

(b)

FIGURE 4: Large range experiment of continuous FLG channel liquid container FET. (a) $I_{\mathrm{DS}}$ versus time response under different concentrations of $\mathrm{pH}$ buffer solution and (b) sensitivity linear response towards $\mathrm{pH}$ value $(\mathrm{pH}=7.0, \mathrm{pH}=10.0, \mathrm{pH}=11.0$, and $\mathrm{pH}=13.0$; $V_{g}=0 \mathrm{~V}$ and $\left.V_{\mathrm{DS}}=0.1 \mathrm{~V}\right)$.

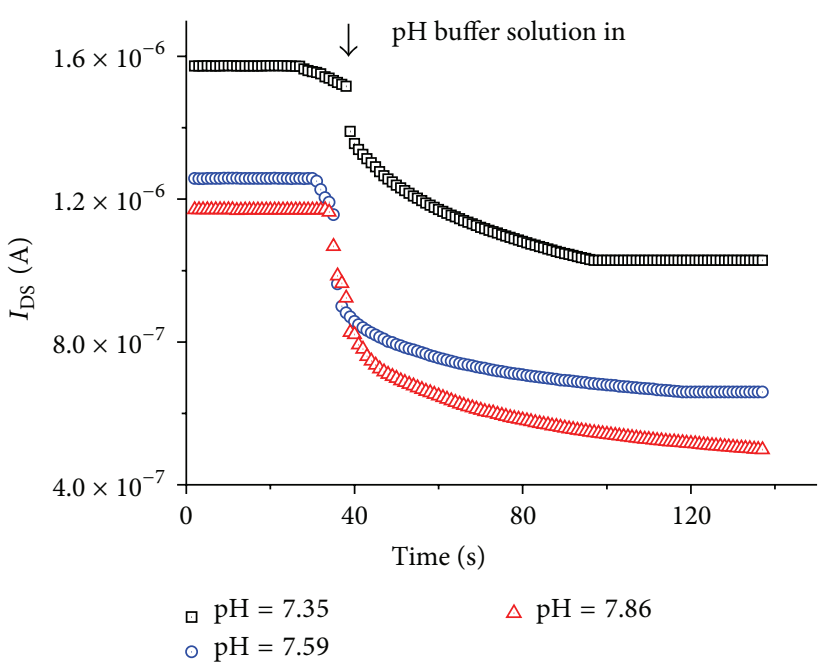

(a)

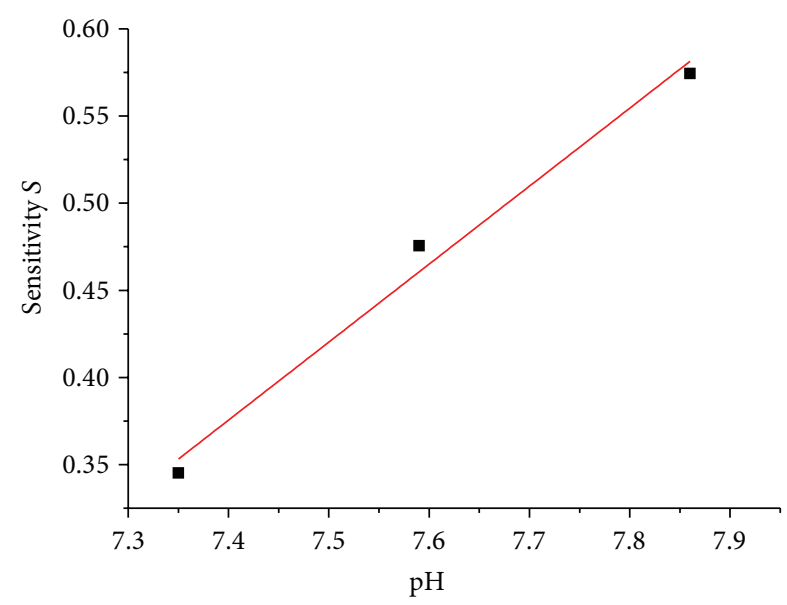

(b)

FIGURE 5: High resolution experiment of quasi-continuous MG channel liquid container FET. (a) $I_{\text {DS }}$ versus time response under different concentrations of $\mathrm{pH}$ buffer solution and (b) sensitivity linear response towards $\mathrm{pH}$ value $\left(\mathrm{pH}=7.35, \mathrm{pH}=7.59\right.$, and $\mathrm{pH}=7.86 ; V_{g}=0 \mathrm{~V}$ and $\left.V_{\mathrm{DS}}=0.1 \mathrm{~V}\right)$.

\section{Conclusions}

We have demonstrated a simple method to fabricate both FLG and MG graphene channel liquid container field effect transistor $\mathrm{pH}$ sensors. An interdigital pattern microtrench, which is used as microcontainer for inhaling liquid ion, was fabricated on $\mathrm{SiO}_{2}$ layer. FLG is less than 10 layers and MG is single crystal and monolayer. Our results show that FLG graphene channel FET has faster response than that of MG after adsorption of the measured molecule and ion at the room temperature. Both resolution and output sensitivities of $\mathrm{MG}$ on $\mathrm{pH}$ value are one order of magnitude higher than those of FLG. The device can be applied to other fields as gas sensor and even biological sensors. MG is suitable for high resolution normal human body $\mathrm{pH}$ testing. Most importantly, the concept of selecting the appropriate structure of graphene according to the different analyte testing requirements may provide a new insight about a new approach for graphene sensor.

\section{Conflict of Interests}

The authors declare that there is no conflict of interests regarding the publication of this paper. 


\section{Acknowledgments}

This work was financially supported by grants from the National Natural Science Foundation of China (nos. 91123018, 61172040, and 61172041), Shaanxi Natural Science Foundation (2014JM7277), and the Fundamental Research Funds for the Central Universities.

\section{References}

[1] K. S. Novoselov, A. K. Geim, S. V. Morozov et al., "Electric field in atomically thin carbon films," Science, vol. 306, no. 5696, pp. 666-669, 2004.

[2] A. K. Geim and K. S. Novoselov, "The rise of graphene," Nature Materials, vol. 6, no. 3, pp. 183-191, 2007.

[3] S. Yoo, X. Li, Y. Wu, W. Liu, X. Wang, and W. Yi, “Ammonia gas detection by tannic acid functionalized and reduced graphene oxide at room temperature," Journal of Nanomaterials, vol. 2014, Article ID 497384, 6 pages, 2014.

[4] W. Wu, Z. Liu, L. A. Jauregui et al., "Wafer-scale synthesis of graphene by chemical vapor deposition and its application in hydrogen sensing," Sensors and Actuators B: Chemical, vol. 150, no. 1, pp. 296-300, 2010.

[5] R. Pearce, T. Iakimov, M. Andersson, L. Hultman, A. L. Spetz, and R. Yakimova, "Epitaxially grown graphene based gas sensors for ultra sensitive $\mathrm{NO}_{2}$ detection," Sensors and Actuators, B: Chemical, vol. 155, no. 2, pp. 451-455, 2011.

[6] R. K. Joshi, H. Gomez, F. Alvi, and A. Kumar, "Graphene films and ribbons for sensing of $\mathrm{O}_{2}$, and $100 \mathrm{ppm}$ of $\mathrm{CO}$ and $\mathrm{NO}_{2}$ in practical conditions," The Journal of Physical Chemistry $C$, vol. 114, no. 14, pp. 6610-6613, 2010.

[7] R. Arsat, M. Breedon, M. Shafiei et al., "Graphene-like nanosheets for surface acoustic wave gas sensor applications," Chemical Physics Letters, vol. 467, no. 4-6, pp. 344-347, 2009.

[8] P. K. Ang, W. Chen, A. T. S. Wee, and P. L. Kian, "Solutiongated epitaxial graphene as $\mathrm{pH}$ sensor," Journal of the American Chemical Society, vol. 130, no. 44, pp. 14392-14393, 2008.

[9] Y. Ohno, K. Maehashi, Y. Yamashiro, and K. Matsumoto, "Electrolyte-gated graphene field-effect transistors for detecting $\mathrm{pH}$ and protein adsorption," Nano Letters, vol. 9, no. 9, pp. 3318$3322,2009$.

[10] N. Mohanty and V. Berry, "Graphene-based single-bacterium resolution biodevice and DNA transistor: interfacing graphene derivatives with nanoscale and microscale biocomponents," Nano Letters, vol. 8, no. 12, pp. 4469-4476, 2008.

[11] Y. X. Huang, X. C. Dong, Y. X. Liu, L. J. Li, and P. Chen, "Graphene-based biosensors for detection of bacteria and their metabolic activities," Journal of Materials Chemistry, vol. 21, no. 33, pp. 12358-12362, 2011.

[12] C. Shan, H. Yang, J. Song, D. Han, A. Ivaska, and L. Niu, "Direct electrochemistry of glucose oxidase and biosensing for glucose based on graphene," Analytical Chemistry, vol. 81, no. 6, pp. 2378-2382, 2009.

[13] T. Kuila, S. Bose, P. Khanra, A. K. Mishra, N. H. Kim, and J. H. Lee, "Recent advances in graphene-based biosensors," Biosensors and Bioelectronics, vol. 26, no. 12, pp. 4637-4648, 2011.

[14] F. Schedin, A. K. Geim, S. V. Morozov et al., "Detection of individual gas molecules adsorbed on graphene," Nature Materials, vol. 6, no. 9, pp. 652-655, 2007.
[15] N. Tombros, A. Veligura, J. Junesch et al., "Large yield production of high mobility freely suspended graphene electronic devices on a polydimethylglu-tarimide based organic polymer," Journal of Applied Physics, vol. 109, no. 9, Article ID 093702, 2011.

[16] Z. G. Cheng, Q. Li, Z. J. Li, Q. Y. Zhou, and Y. Fang, "Suspended graphene sensors with improved signal and reduced noise," Nano Letters, vol. 10, no. 5, pp. 1864-1868, 2010.

[17] X. Li, J. Zhang, Q. Li et al., "A controllable preparation method for IC-oriented large scale single crystal graphene," Journal of Xian Jiaotong University, vol. 48, no. 6, pp. 103-109, 2014.

[18] X. Li, W. Cai, J. An et al., "Large-area synthesis of high-quality and uniform graphene films on copper foils," Science, vol. 324, no. 5932, pp. 1312-1314, 2009.

[19] L. Gomez de Arco, Y. Zhang, A. Kumar, and C. Zhou, "Synthesis, transfer, and devices of single- and few-layer graphene by chemical vapor deposition," IEEE Transactions on Nanotechnology, vol. 8, no. 2, pp. 135-138, 2009.

[20] A. Reina, X. Jia, J. Ho et al., "Large area, few-layer graphene films on arbitrary substrates by chemical vapor deposition," Nano Letters, vol. 9, no. 1, pp. 30-35, 2009.

[21] X. Li, Y. Zhu, W. Cai et al., "Transfer of large-area graphene films for high-performance transparent conductive electrodes," Nano Letters, vol. 9, no. 12, pp. 4359-4363, 2009.

[22] T. Someya, J. Small, P. Kim, C. Nuckolls, and J. T. Yardley, "Alcohol vapor sensors based on single-walled carbon nanotube field effect transistors," Nano Letters, vol. 3, no. 7, pp. 877-881, 2003.

[23] E. Stern, A. Vacic, and M. A. Reed, "Semiconducting nanowire field-effect transistor biomolecular sensors," IEEE Transactions on Electron Devices, vol. 55, no. 11, pp. 3119-3130, 2008.

[24] S. K. Yoo, S. Yang, and J. H. Lee, "Hydrogen ion sensing using schottky contacted silicon nanowire FETs," IEEE Transactions on Nanotechnology, vol. 7, no. 6, pp. 745-748, 2008. 

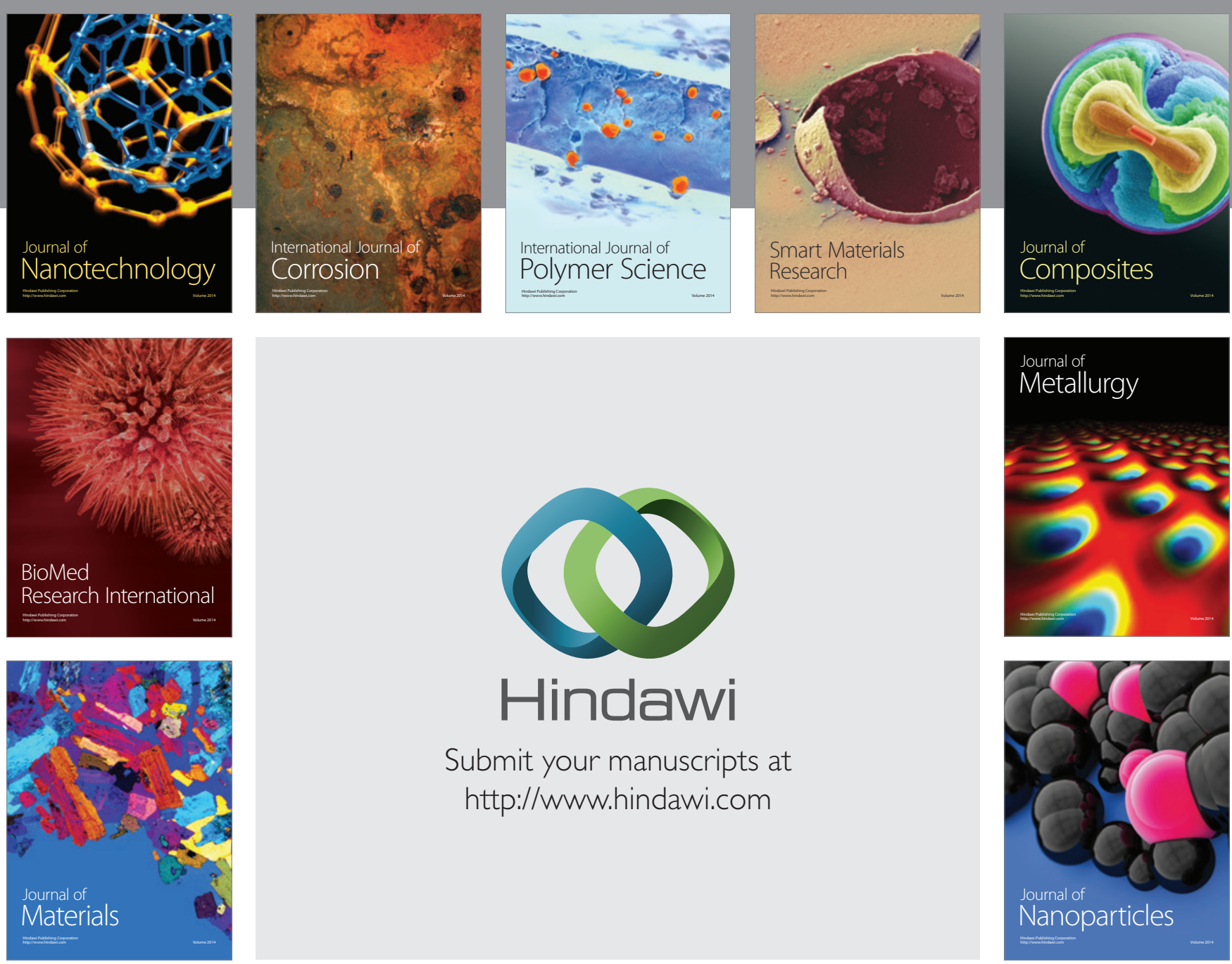

Submit your manuscripts at http://www.hindawi.com
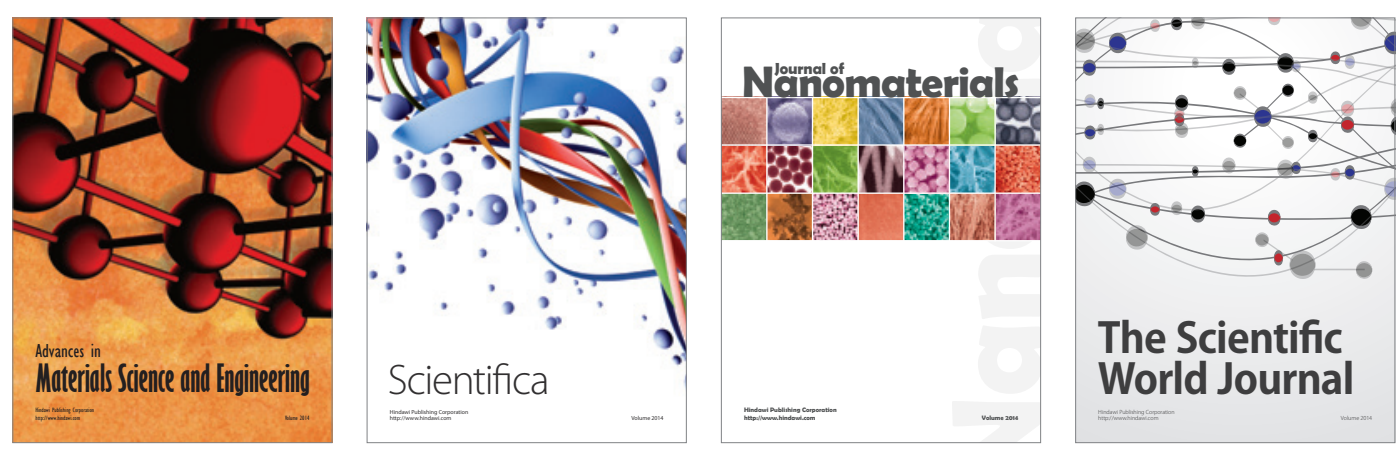

\section{The Scientific World Journal}
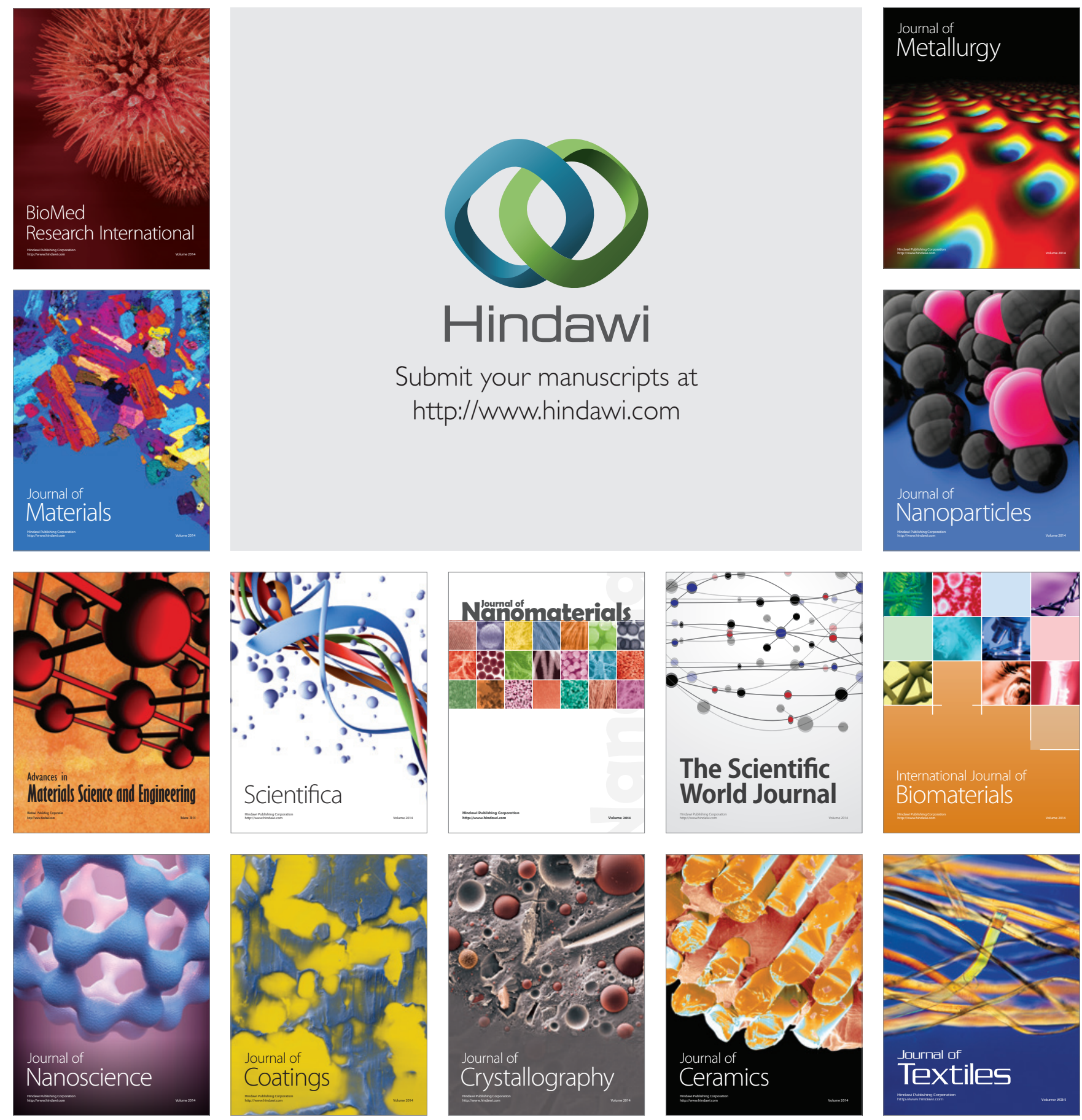